\title{
Infectious Diseases of North American Black Bears (Ursus americanus): Parasites (Part 2)
}

\author{
D. Zimmerman, DVM, ${ }^{1}$ M. A. Mitchell, DVM, MS, $\mathrm{PhD}^{2}$ \\ ${ }^{1}$ Memphis Zoo, Memphis, Tennessee \\ ${ }^{2}$ Louisiana State University, School of Veterinary Medicine, Baton Rouge, Louisiana
}

\begin{abstract}
Black bears (Ursus americanus) serve as an important keystone species within an ecosystem and can serve as sentinels for environmental health. Wildlife rehabilitators, biologists, and veterinarians working with these animals should familiarize themselves with infectious diseases commonly associated with these ursids. The purpose of this paper is to provide a literature review of the common endoparasites and ectoparasites associated with black bears.
\end{abstract}

\section{INTRODUCTION}

This is the second installment in a two-part series to review common infectious diseases of free-ranging American black bears (Ursus americanus). The purpose of this work is to provide a review of the literature pertaining to endoparasites and ectoparasites observed in black bears from North America. Numerous reports on parasites known to infect the black bear were reviewed and grouped by agent, location/year, and prevalence. When significant, correlations to age, sex, and season, as well as relationships to other species and pathogenicity of the agent, are discussed.

\section{ECTOPARASITES}

Bears are susceptible to many of the same ectoparasites encountered in domestic species, including fleas, lice, ticks, and mites. Often these ectoparasites serve as vectors for the transmission of infectious diseases to the bear and should be removed to minimize the likelihood of disease transmission. Wildlife veterinarians and rehabilitators working with bears should also take special precautions when working with bears to minimize the likelihood of infestation by the bear's ectoparasites.

Dr. Zimmerman graduated from Ross University after a clinical year at Louisiana State University. She completed an internship in zoological medicine at Omaha's Henry Doorly Zoo and is currently the associate veterinarian at Memphis Zoo.

Dr. Mitchell is a former member of the NWRA board of directors. He is Assistant Professor of Zoological Medicine and Director of the Wildlife Hospital of Louisiana at Louisiana State University in Baton Rouge, LA.
Arthropods (Insecta). Flea infestations are a concern in black bears in regions where the climate favors the reproductive cycle of the flea. In the northern United States, flea infestations would be most problematic during the late spring, summer, and early fall when the temperature is greater than 60 degrees $\mathrm{F}$ (15 degrees $\mathrm{C})$ and the humidity is greater than 50 percent. In the southeastern United States, flea infestations might be expected to occur year round. Currently, reports of flea infestations in the literature are limited to cases in Michigan and Montana. Because flea infestations are common in free-ranging bears, routine reports from different areas within the country would not be expected. All of the injured Louisiana black bears (U. americanus luteolus) $(\mathrm{n}=5)$ presented to the Louisiana State University Wildlife Hospital of Louisiana were flea infested (Mitchell, unpublished data). In addition, free-ranging black bears being studied in Louisiana also were infested with fleas (Mitchell, unpublished data). Chaetopsylla hiberculaticeps ursi was collected from black bears in Montana. The prevalence of infestations was low $(2 \%)$ in this population of bears (Jonkel and Cowan 1971). Flea infestations in bears can be treated using the same treatment used for domestic dogs. At the Wildlife Hospital of Louisiana, fipronil (Frontline ${ }^{\circledR}$, Merial, Duluth, GA) is used to treat flea infestations. The environment must also be cleaned to eliminate any eggs or larval stages.

Lice infestations are a common finding in freeranging black bears and are documented as being more widespread across North America than flea infestations. Trichodectes pinguis euarctidos is the only species of louse reported on black bears, and it has been recovered from bears in Montana, Michigan, and Wisconsin over the past 30 years (Jonkel and Cowan 1971; Rogers 1975; Manville 1978). Lice infestations in bears are generally categorized as high, with thousands of lice infesting a single bear. Heavy flea 
and tick infestations often accompany lice infestations as well. Prior to 1970, the highest prevalence of Trichodectes reported was seven percent in New York (King et al 1960). Ivermectin $(0.2 \mathrm{mg} / \mathrm{kg}$ once, repeated two times at two-week intervals) has been used successfully to treat lice in Louisiana black bears.

Arthropods (Acarina). Several tick species parasitize black bears. Dermacentor variabilis is the most common tick found on black bears in North America. Dermacentor andersoni and D. albipictus have also been isolated from free-ranging black bears. Amblyomma maculatum and A. americanum have been collected from Florida black bears. Dermacentor variablis, A. americanum, and A. maculatum have all been associated with tick paralysis (Strickland et al 1976). These ticks parasitize species that share habitat with the black bear in Florida such as white-tailed deer (Odocoileus virginianus), wild hogs, and Florida panthers (Felis concolor coryii) (Forrester 1992). Ixodes dammini and I. scapularis have been found to parasitize the black bear. Ixodes dammini is a vector of Lyme disease. Lyme disease has not been described in the black bear, but tick paralysis has been reported (Wilkinson 1970). Fipronil can be used to eliminate ticks from black bears. The environment in which the bear is housed should also be treated to eliminate larval and nymph stages.

Clinical mange in the black bear has been linked to Demodex, Sarcoptes, and Ursicoptes. Demodecosis in bears is unlike that in dogs, as different lesions have been observed, including crusty, scaly lesions with moderate alopecia; mites could not be found on asymptomatic bears (Forrester et al 1993; Foster et al 1998). The mites were most commonly observed in hair follicles devoid of hair and at the infundibulum of sebaceous glands. The distribution of the mites was associated primarily with the dorsum, ears, and forelimbs (Forrester et al 1993). Because Demodex infection is believed to be a sequela of an immunosuppressive disorder (genetic or acquired), it is not surprising that only a small percentage of black bears had signs and that most positive bears were found in close proximity to each other (Foster et al 1998). Affected bears have been reported in Florida and northern Wisconsin, but the prevalence, distribution, and significance of infestation is unknown. Ivermectin $(0.2 \mathrm{mg} / \mathrm{kg}$ subcutaneous [SQ] once, repeated twice in two-week intervals) may prove useful as a treatment for demodecosis.

Only three clinical cases of sarcoptic mange (Sarcoptes scabiei) have been reported in black bears. These bears, found in Michigan, were thought to be a sow and her offspring. Their skin had scaly, crusty, and keratotic lesions but was not pruritic (Schmitt et al 1987), and they offered two hypotheses to explain the rarity of sarcoptic mange in black bears. First, black bears are solitary in nature, having little contact with animals frequently infested with mange (e.g., red fox [Vulpes vulpes] and coyote [Canis latrans]). However, this hypothesis assumes interspecies transmission, which may be unlikely even if sarcoptic mange is considered a zoonotic disease. Second, bears may have an innate or acquired resistance to Sarcoptes infection. However, in humans, sarcoptic mange is generally found in immunodepressed individuals and, like demodecosis, may be associated with immunosuppression in black bears.

Another mite linked with clinical mange in black bears is Ursicoptes americanus, known only from its description on three black bears at the Kansas Zoo (Yunker et al 1980). The morphology of this mite is similar to that of the sarcoptiform mites, and the general presentation includes characteristic mild to severe facial dermatitis in affected animals (Schmietzel and Fowler 1984). Related mites, found in squirrel monkeys (Saimiri sp.), are known to inhabit hair follicles without producing clinical mange (Yunker et al 1980). Partial clinical recovery after one year suggests the infection is self-limiting (Yunker et al 1980). Treatment may speed recovery using the demodecosis protocol for dogs (Schmietzel and Fowler 1984).

\section{ECTOPARASITE SUMMARY}

The data suggest individual variation in susceptibility to ectoparasites as in some cases in which few bears are infested, but their infestations are heavy. These findings indicate a possible link between ectoparasitism and immunosuppression. Jonkel and Cowan (1971) suggested that subadult bears probably have more difficulty resisting ectoparasites because they are in poorer condition than adults. They also found a geographic variation in parasite distribution and suggested that this may be associated with a higher local density of rodent species. However, no clear regional distribution was evident from combining reports. Pathologic effects of these ectoparasites are rare in the black bear. Clinical mange is rarely observed, suggesting that it is more likely to be found in immunosuppressed individuals and/or is often self-limiting.

\section{ENDOPARASITES}

Nematodes. Baylisascaris transfuga, a ubiquitous ascarid, was reportedly the most common endoparasite of the black bear throughout its range in Canada and the northern United States (Manville 1978). More recent studies have reported a moderate prevalence (29\%, $\mathrm{n}=104$ ) in black bears in the southeastern United 
States (Pence et al 1983) and a low prevalence (8.3\%, $\mathrm{n}=12$ ) in bears in New Brunswick, Canada (Duffy et al 1994). The highest prevalence of B. transfuga is associated with mountainous regions, 71 to 84 percent (Pence et al 1983). The highest prevalence among southeastern United States black bears was observed in juvenile males (Pence et al 1983). Although it may be inferred that a higher prevalence would be observed in adult males than in adult females, because of their larger home range, this was not the case in southeastern black bears (Pence et al 1983). Adult B. transfuga are located in the small and large intestine and derive their nourishment from ingested materials. In most bears, it appears that this helminth is lost prior to denning (Manville 1978). Larvae ingested in the summer and fall fail to develop but persist over winter. When the bear resumes eating, the larvae then grow into adults and produce eggs, which explains why the prevalence of eggs in the feces increases from spring to fall (Frechette and Rau 1978). Significant pathologic effects of $B$. transfuga are not readily evident in most infected bears, but the consequences of infection warrant further investigation because of the possibility of larval migrans disease and the ascarid's neurotropic affinity (Crum et al 1978).

Lagochilascaris sp. has been documented in Florida black bears (4\% prevalence). In one case, granulomas associated with L. sprenti were discovered in the spleen, and eggs were observed in the liver (Forrester et al 1993). Adult Lagochilascaris sp. has been located in the stomach and small intestine (Pence et al 1983). Toxascaris leonina also has been found in the small intestines of two black bears $(n=46)$ (Conti et al 1983) in Florida. Perhaps other studies have not routinely screened for this parasite in the black bear, or the black bear is an incidental host.

Capillaria aerophila, C. plica, and C. putorii infestations have all been reported in black bears. Adult C. aerophila nematodes are usually found in the lungs and trachea. This parasite has been reported only in southern black bears, and the highest prevalence (71 percent) was found among bears in the southern coastal plain. Male bears in the south were also more likely than females to be infested with C. aerophila (Pence et al 1983). Catarrhal bronchitis was the most common clinical pathologic finding associated with this parasite (Crum et al 1978). Unlike C. aerophila, C. putorii has been reported in black bears from all regions of North America. The prevalence of C. putorii among southern bears is 25 percent (Pence et al 1983). The prevalence of C. putorii was also highest among juvenile males, 40 percent (Pence et al 1983). While C. aerophila is most frequently associated with bears found in topo- graphically flat regions, C. putorii infestations are more likely to be found in bears in mountainous regions, 42 to 47 percent (Pence et al 1983). Although adult C. putorii are located in the stomach, this parasite has not been associated with any pathology in bears. C. plica, found in the urinary bladder, has been reported only in bears from the south, and at two percent is the least prevalent of the Capillaria species in black bears (Pence et al 1983).

Dirofilaria ursi (synonymous with D. desportesi) is a common parasite of black bears throughout the northern United States and Canada (Manville 1978), and it is the most common helminth of black bears in Quebec (Frechette and Rau 1977). The prevalence of D. ursi ranges from 4 to 33.7 percent in North American black bears (Jonkel and Cowan 1971; Duffy et al 1994). This subcutaneous filarid has been found in the connective tissue, peritoneal cavity, and periesophageal area of the thoracic inlet (Rogers 1975; Dies 1979), but it is not regarded as a significant pathogen of the black bear. Microfilaria of D. ursi can be detected in blood smears and lung tissue of patent infections (Crum et al 1978). Because these diagnostic samples are not routinely collected for general surveys, the prevalence and distribution of D. ursi is likely underestimated (Pence et al 1983). Black flies (Simulium sp.) may be vectors of filarid nematodes (Addison et al 1978); however, little is known about the life cycle of this parasite.

Gongylonema pulchrum, a spirurid nematode, was the most frequently encountered and widely distributed parasite in the study of black bears by Crum et al (1978). G. pulchrum is a widespread generalist parasitizing a variety of carnivores and other mammals (Levine 1968). The intermediate hosts, Blattaria and Coleoptera, are readily consumed by bears (Crum et al 1978). The worm may be found in the tongue or esophagus, but infection of the esophagus is more common. The prevalence of this parasite is correlated to region, as an increased percentage of bears in the northern mountains of eastern North America are infected, 41 to 71 percent (Pence et al 1983). G. pulchrum has not been reported in Michigan, Minnesota, Montana, New York, Wisconsin, Alberta, Ontario, or Quebec. Thus, Pennsylvania may represent the northern limit of infection in black bears with a prevalence of 33.1 percent (Kirkpatrick et al 1986). When isolated, virtually all female worms contained eggs, indicating that the black bear is a natural host for $G$. pulchrum (Crum et al 1978).

Molineus barbatus, a trichostrongylid nematode, appears to be non-host-specific and occurs commonly in raccoons (Procyon lotor), skunks (Mephitidae 
sp.), and bobcats (Lynx rufus) in the southeast (Crum et al 1978). Domestic dogs (Canis lupus familiaris) and cats (Felis silvestris catus) can also be infected with $\mathrm{M}$. barbatus (Crum et al 1978). In black bears, M. barbatus has been found in the small intestine. The prevalence of infection in black bears is highest in the southern regions, 41 to 44 percent, as reported by Pence et al (1983).

Strongyloides spp. represent the third most prevalent nematode in black bears according to Crum et al (1978). The prevalence of this parasite is highest in bears from coastal areas, 64 to 83 percent (Pence et al 1983). There is also a difference in the prevalence of Strongyloides spp. infestations between adult $(>3.75$ years) (61 to $80 \%)$ and juvenile bears $(<1.5$ years) (31 to 50\%) (Crum et al 1978; Pence et al 1983). Adult males were also more likely to be positive than females, and this was attributed to the larger home ranges of males as compared to females (Pence et al 1983). The species of Strongyloides isolated from these bears could not be identified but reportedly resembled S. procyonis and S. stercoralis. This intestinal nematode can be pathogenic to young animals (Levine 1980).

Dirofilaria immitus (heartworm) has been found in 31 percent of black bears from the northern coastal plains and 13 percent of bears from the southern coastal plains (Pence et al 1983). In one case, five adult worms were recovered from the right ventricle and pulmonary artery (Johnson 1975). None of the female heartworms contained microfilaria. Based on this single finding, the black bear was considered an unsuitable host for the completion of D. immitus life cycle (Johnson 1975). However, in a later study, microfilaria were recovered from female D. immitus in a black bear. All of the infected animals were greater than 2.5 years old and were found along coastal North Carolina (Crum et al 1978).

Arthrocephalus lotoris, the raccoon hookworm, has only been isolated from black bears in one study during the past 30 years (Crum et al 1978). The prevalence of infection was 23 percent $(n=53)$ in bears from the southeastern US. Within this sample there was a significant difference between bears found in the coastal regions, in which 42 percent were infested, compared to the mountainous regions, in which 12 percent were infested. The higher prevalence in the coastal region is similar to the incidence of other parasites identified in these areas, such as $M$. ingens, and likely reflects cross contamination with raccoons (Crum et al 1978).

Physaloptera, or stomach worms, are not common in black bears as reported by Pence et al 1983 and Conti et al 1983. Fourteen to 15 percent of the animals were infested. Immature stages of Physaloptera have been found in the stomachs of bears (Crum et al 1978). Few adult worms have been isolated and were identified as P. rara (Pence et al 1983). In areas where the infections were reported, Pence et al (1983) observed a prevalence of 24 percent in the southern coastal plains. Again, P. rara is a parasite typically associated with raccoons. Cyathospirura sp., another stomach nematode, has also been reported in the black bear with low prevalence of one percent in the southeast and five percent in the northern mountains, suggesting that black bears are probably accidental hosts (Pence et al 1983).

Ancylostoma caninum, the dog hookworm, is found primarily in southern regions of the United States where four to six percent of bears are infested (Pence et al 1983). Only infertile female A. caninum have been found in the small intestines of infected bears, which, coupled with the low prevalence, suggests that the black bear is an incidental host (Crum et al 1978). Another hookworm, Uncinaria yukonensis, has been found in three to six percent of black bears from Quebec and Montana (Frechette and Rau 1977; Pence et al 1983).

Crenosoma sp., a strongylid, possibly C. vulpis, has been isolated from the trachea and lungs of black bears, although it is usually found in the bronchi and bronchioles of canids. This parasite has been previously associated with verminous pneumonia in the black bear (King et al 1960). Although this parasite has been isolated from bears inhabiting mountainous regions (11 to $12 \%$ ), some cases have been reported from bears in the southern coastal plains (6\%) (Pence et al 1983; Conti et al 1983).

Dracunculus sp., a spirurid parasite generally found in subcutaneous tissues, has been seen in the musculature of two percent of black bears in the southern coastal plains of North America (Pence et al 1983). The low prevalence of another spirurid, Gnathostoma sp., in black bears suggests the bear is an accidental host. Immature stages have been found in the liver (Crum et al 1978; Pence et al 1983). One adult worm was isolated from a Florida black bear and was identified as G. didelphis. Larvae of another spirurid nematode, Spirocerca lupi, have been found in the aorta of one black bear (Pence et al 1983).

The prevalence of Trichinella spiralis in black bears ranges from 0.37 to 15.6 percent. Research has established a relationship between the sylvatic and domestic life cycles of this nematode. Bears appear to be susceptible to trichinosis because of their opportunistic feeding behavior (Manville 1978) and scavenging and predation of infected rodents (Ruppanner et al 1982). 
Black bears may also acquire infections from infected pork at dumpsites, and an increased prevalence has been correlated to highly populated areas (Schad et al 1986). Not all black bears, however, have access to garbage, and scavenging on carrion and/or predation on wildlife likely plays a more important role in the transmission of sylvatic trichinosis (Schad et al 1986). This parasite has been found in black bear tongue tissue from Alaska to Arizona, east to New England, and across Canada (Duffy et al 1994). Trichinosis is endemic in the arctic, with a wide distribution throughout the Northern hemisphere (Zimmermann 1970). Prior to 1970, Rausch (1954) indicated that the black bear was a significant wildlife reservoir, and 21 percent of bears in Alaska were found to have trichinosis. A 1981 to 1983 study of more than 2,000 of the reported 6,000 black bears in Pennsylvania by Schad et al (1986) revealed a low (1.8\%) prevalence of trichinosis. T. spiralis is considered a potential public health hazard in Pennsylvania because of the state's significant swine population (Schad et al 1986). High intensity infection (>100 larvae per gram of tissue) was observed in one- and two-year old bears, as well as in older bears, refuting suggestions that older, larger carnivores may be more likely to harbor heavy infections than younger animals because they live longer.

The diet of black bears in Pennsylvania includes many possible sources of $T$. spiralis, such as garbage, rodents, and carrion. Schad reported that 3.2 percent of small furbearers in Pennsylvania are infected with T. spiralis, with some species exhibiting a prevalence greater than ten percent and more than 15 percent of red foxes exhibiting infestations (Schad et al 1986). Butler and Khan (1992) found few larvae in bear tongue and diaphragm samples, suggesting that the black bear's involvement in the sylvatic cycle of T. spiralis in Eastern Canada (Labrador) is limited. In addition, no infection was observed in tongue, masseter, or diaphragmatic musculature from 73 black bears in the Atlantic provinces. Smith (1978) concluded that the black bear was not involved in the sylvatic cycle of T. spiralis. Nutter et al (1998) found no positive samples in North Carolina black bears, but the sample size was small ( $\mathrm{n}=79)$, and the geographic study area was narrow. The absence of Trichinella sp. in one study of black bears in the southeastern US may be a result of analyzing frozen tissues or an indication of low prevalence in this region (Crum et al 1978). The latter suggestion is supported by the lack of reported human infections in the southeast. In such cases, one larva per gram of tissue produces clinical trichinosis in humans (Duffy et al 1994; LeCount 1981).

Therefore, even if the prevalence of Trichinella sp. in black bears is low, the zoonotic nature of the parasite is a concern as trichinosis can cause serious illness in humans (Dubey et al 1994). Between 1971 and 1976, 7.8 percent of all clinical human trichinosis cases in the United States were traced to ingestion of infected bear meat, which increased to 14.6 percent between 1982 and 1986 (Smith 1978). Research has shown that the Trichinella sp. from black bear may not be T. spiralis, which is usually found in swine, but a sylvatic genotype designated as Trichinella T5 with unknown human infectivity (Dubey et al 1994). No sex- or age-related differences in the prevalence or intensity of Trichinella sp. infections have been reported (Schad et al 1986). This is interesting because adult male bears feed more frequently at dumpsites than female bears and would be expected to exhibit higher prevalence of Trichinella sp. infection (Rogers 1975).

Cestodes. Diphyllobothrium latum, the broad fish tapeworm, is synonymous with $D$. ursi. The prevalence of eggs (strobilae) in bear feces varies seasonally, with the highest loads observed during the summer and fall and the lowest loads in the spring (Frechette and Rau 1978). Reduction in egg shedding from fall 1971 to spring 1972 showed a drop from 70 to 21 percent and was attributed to the expulsion of gravid adult worms prior to denning (Frechette and Rau 1978). The presence of ova in feces in early spring is difficult to explain unless, perhaps, D. ursi destrobilate, but persist, during the denning period and resume proglottization subsequent to arousal. Many questions remain regarding the life cycle of this parasite, including identifying the intermediate host and determining the prepatent period. Current thinking is that black bears acquire D. ursi in the fall from brook trout (Salvelinus fontinalis) (Frechette and Rau 1978). Although reportedly common in black bears and humans throughout northeastern Minnesota in the early 1900s, this parasite is uncommon in Minnesota now with zero percent prevalence in 962 bears (Rogers 1975).

Several taneid tapeworm species have been observed in the black bear. Taenia saginata infection is probably acquired by eating meat scraps at ranger stations and trap sites (Jonkel and Cowan 1971). The prevalence of this parasite in bears is low, as only one case has been reported (Jonkel and Cowan 1971). Another species believed to be Multiceps serialis exhibited a prevalence of 29 percent in Minnesota bears (Rogers 1975). This tapeworm infects black bears that feed on snowshoe hares (Lepus americanus), which are the intermediate hosts. Reports of these infections are limited to the northwest portion of North America and Minnesota. Taenia krabbei and T. hydantigena 
were found in the intestinal tracts of young bears in Quebec and were reported in Canada where bears scavenge on moose carcasses (Frechette and Rau 1977; Duffy et al 1994). Wild cervids and domestic livestock are documented intermediate hosts of $T$. hydantigena (Frechette and Rau, 1977). The prevalence of T. krabbei and T. hydantigena in Canada are 3 to 25 percent and 3.3 to 6 percent, respectively (Frechette and Rau 1977; Dies 1979; Duffy et al 1994). Because these species of tapeworms are primary parasites of wolves (Canis lupus), the definitive host in North America, and because of the low prevalence of infection in black bears (Dies 1979), it is unlikely that bears play a significant role in the epidemiology of these parasites (Frechette and Rau 1977). Three cases of T. solium cysticercosis in skeletal and cardiac muscle of California black bears have been reported. Humans infected with the definitive stage of T. solium are thought to serve as the source of cysticercosis in bears, which would become infected through the ingestion of human feces contaminated with ova (Theis et al 1996).

Spirometra mansonoides spargana infections have been discovered in black bears of the southern coastal plains at a prevalence of 25 percent (Pence et al 1983), and are known to have pathological effects. Because this parasite is located in the musculature, human infection may result from consuming viable spargana in the meat of wild animals (Crum et al 1978). Therefore, Spirometra infection in black bears is of important public health significance. Currently, the only cases reported in black bears have occurred in southern coastal plains (Pence et al 1983).

Trematodes. Pharyngostomoides procyonis has been found in the small intestine of black bears (Conti et al 1983). Heterobilharzia americana, usually a parasite of dogs, has been isolated from one black bear in Florida ( $\mathrm{n}=37)$ by Forrester (1992). In addition, Alaria marcianae has been reported only once, at one percent prevalence, by Addison (1978) in central Ontario, Canada.

Only one case of Prouterina wescotii infection in a black bear has been reported. The bear, discovered in Idaho, was emaciated and weak with nasal discharge and progressive neurological signs, eventually leading to death (Foreyt et al 1996). Findings at necropsy showed that the trematode had affected the brain, lungs, and nasal sinuses. Based on these findings, it is important to examine the nasal sinuses of bears with a nasal discharge for trematodes and to evaluate the mucus for trematode eggs. The normal definitive host of $P$. wescotii is unknown, as is whether the black bear was a natural or aberrant host (Foreyt et al 1999). A study of 46 black bears in Oregon yielded no evidence of $P$. wescotii infection (Foreyt et al 1999).

Although a black bear has been experimentally infected with the salmon poisoning fluke, Nanophyetus salmincola, natural infections in free-ranging bears have not been reported. Infection remains a concern because the bear is a fish-eating omnivore indigenous to the enzootic region of this trematode (Farrell et al 1973).

Acanthocephala. Macracanthorhynchus ingens, a common small intestinal parasite of raccoons in the southeastern United States, has been found in 48 percent of black bears from the southeastern US. Prevalence was highest in coastal areas, ranging from 50 to 74 percent and correlating with high densities of raccoon populations for cross-transmission and/or the intermediate hosts, scarabacid beetles (Crum et al 1978). Macracanthorhynchus ingens has large, powerful hooks that can cause mechanical damage to the intestinal lining of bears (Petrochenko 1971).

Protozoa. Toxoplasma gondii is the most commonly reported protozoan infecting black bears, with serologic evidence of exposure reported in 27 percent of California bears, 38 to 100 percent of Florida bears, 21 to 78 percent of Pennsylvania bears, eight percent of Idaho bears, 84 percent of North Carolina bears, 15 to 43 percent of Alaska bears, and 33 percent of bears in Ontario, Canada. Thus, black bear exhibit the highest seroprevalence of any animal or human population tested in the United States to date (Nutter et al 1998). Black bears often have antibody titers greater than 1:500, eliminating any question of false positives (Burridge et al 1979; Zarnke et al 2000). In bears from Pennsylvania, the prevalence in adults was 90 percent while the prevalence in juveniles was 50 percent (Dubey et al 1995). T. gondii has been isolated from the heart and skeletal muscle of black bears (Dubey et al 1994) and has an apparent affinity for heart muscle in bears (Dubey et al 1995). Black bears can harbor viable T. gondii cysts (Dubey et al 1994), and necrotizing pancreatitis has consistently been reported in association with $T$. gondii. This is of significant concern because toxoplasmosis can cause serious illness in humans after the ingestion of undercooked bear meat.

Transmission of $T$. gondii can be transplacental or through contaminated food and water. The definitive feline host is unknown; however, bobcats are suspected in most regions (Burridge et al 1979). Transmission from domestic cats would be unlikely, and feral cats do not normally survive outside established communities (Zarnke et al 2000). Lynx (Lynx sp.) are the 
only free-ranging felids in Alaska and are a potential source of infection for black bears because lynx are high in the food chain (Zarnke et al 2000). Ruppanner et al (1982) found that the prevalence of toxoplasmosis in black bears, 27 percent, was greater than that in rodents, three percent, but less than in bobcats, 69 percent, in northern California. It is similar to that found in other non-feline species of wild carnivores such as gray fox (Urocyon cinereoargenteus), 27 percent, and coyote, 28 percent. In Pennsylvania, where the estimated black bear population is about 7500 , all counties had seropositive bears with a range of 25 to 100 percent (Quinn et al 1976). Nutter et al (1998) found an increased prevalence of T. gondii in female bears compared to males; however, the authors attributed that finding to sampling bias. Titers increase with animal age because of cumulative exposure (Nutter et al. 1998; Binninger et al 1980; Ruppanner et al 1982; Briscoe et al 1993). The ages of Florida black bears infected with $T$. gondii ranged from less than one year to seven years. For most bears, first exposure is thought to occur after the second birthday (Chomel et al 1995). Infection rates also vary with geographic location. It is unknown whether black bears develop clinical toxoplasmosis. There are no reports of the organism causing disease in the black bear (Binninger et al 1980).

Eimeria albertensis and E. borealis have been isolated from Canadian black bears (Hair and Mahrt 1970). These parasites can be differentiated from other coccidia by evaluating them under light microscopy. Eimeria sp. exhibits four sporozoites per oocyst. These parasites do not usually cause clinical disease in adult bears but may be more problematic in juveniles.

Cryptosporidium parvum has been observed in one black bear in Virginia (Duncan et al 1999). Oocysts were found in the small intestine of a cub. Molecular characterization of this parasite revealed a new genotype of C. parvum related to the canine C. parvum genotype, indicating that it was a host-adapted strain (Xiao et al 2000). Because of the similarity of the bear genotype to those of the C. parrum and C. felis found in acquired immune deficiency syndrome (AIDS) patients, this parasite is considered a public health threat. If oocysts were shed by a bear and contaminated the ground water, they could enter a municipal water system and pose a public health risk (Xiao et al 2000).

Muscular and hepatic Sarcocystis sp. infections have been described in low prevalence, 1 to 11 percent, in black bears (Dubey et al 1998; Crum et al 1978). In the first report of sarcocysts in a black bear, no pathological lesions were identified (Dubey et al
1998). However, a fatal case of hepatic sarcocystis was discovered in a black bear in South Dakota (Zemen et al 1993). Lesions were present in the liver, and only schizonts and merozoites were found. In a study of black bears in Oregon, sarcocysts were found in the tongues of two bears whose heads were studied (Foreyt et al 1999). The source of infection (definitive host) and the species of Sarcocystis was not determined.

\section{ENDOPARASITE SUMMARY}

Over the past 30 years, a total of 20 nematode, 3 cestode, 4 trematode, 1 acanthocephalan, and 4 protozoan species have been isolated from black bears. The nematode species were the most frequent parasites, while trematodes were rarely observed. The wide geographic range and omnivorous feeding habits of black bears are the most likely reasons that bears serve as intermediate hosts for a variety of parasites. They also account for the species richness and diversity of the secondary helminth community across their North American range (Pence et al 1983). The most prevalent species observed in the black bear included Baylisascaris transfuga, Capillaria aerophila, Capillaria putorii, Dirofilaria ursi, Diphyllobothrium ursi, Gongylonema pulchrum, Molineus barbatus, Macracanthorhynchus ingens, Spirometra mansonoides, Strongyloides sp., and Toxoplasma gondii. Black bears appear to be natural hosts for these 12 parasites. Because of their predatory and scavenging behavior, black bears are commonly parasitized by other species with moderate to low prevalence. These less prominent parasites indicate that black bears serve as accidental hosts as well.

Clinical disease in black bears has been observed with six parasites, including Capillaria aerophila, Crenosoma sp., Strongyloides sp., Spirometra sp., Prouterina sp., and Sarcocystis sp. The prevalence of Capillaria aerophila, Strongyloides sp., and Macracanthorhynchus sp. should be monitored because these species can cause clinical disease in humans and have been found at relatively high frequencies in black bears.

The presence of endoparasites in black bears appears to be correlated to geographic regions. Almost half the parasites reported to affect black bears were observed exclusively or most commonly along the southeastern coast. These included Arthrocephalus lotoris, Capillaria aerophila, Capillaria plica, Dracunculus sp., Gnathostoma sp., Macracanthorhynchus ingens, Molineus barbatus, Physaloptera rara, Placoconus lotoris, Spirometra mansonoides, and Strongyloides sp. Pence et al (1983) concluded that the helminthic fauna of black bears in the southeastern United States was significantly different from that in black bears throughout the rest of North America. The higher prevalence 
of parasitic helminth species in the southeastern US relates in part to the close relationship between bears and raccoons in this region (Pence et al 1983). The higher density of raccoons in the southeast has resulted in seeding the environment with infective helminth stages (Pence et al 1983). Therefore, black bears serve as intermediate hosts for a number of parasites in common with raccoons, which are the definitive hosts, including Ancylostoma sp., Capillaria plica, Dracunculus sp., Gnathostoma sp., Lagochilascaris sp., Macracanthorhynchus ingens, Physaloptera rara, Placoconus lotoris, Spirometra mansonoides, and Toxascaris leonina. Because black bears and raccoons are omnivores, they serve as indicators for contamination of the environment with parasites, such as T. gondii (Quinn et al 1976). In addition to raccoons, black bears also serve as a host for a number of parasites found in domestic and wild canids, including Ancylostoma caninum, Dirofilaria immitus, Spirocerca lupi, and Toxascaris leonina. Such shared species represent a large secondary parasite community, because black bears often serve as intermediate hosts (Pence et al 1983).

Black bears are definitive hosts for four helminth species, including Baylisascaris transfuga, Dirofilaria ursi, Diphyllobothrium ursi, and Uncinaria yukonensis (Pence et al 1983). Of these, two species, Baylisascaris transfuga and Dirofilaria ursi, appear to be ubiquitous in black bears (Pence et al 1983). These cestodes and nematodes comprise the primary helminth parasites of black bears. In this role, their long-term survival is dependent on growth of the host population. Therefore, these parasites are not routinely associated with mortalities, except in the young, old, and immunocompromised (Pence et al 1983).

\section{LITERATURE CITED}

Addison, E. M., M. J. Pybus, and H. J. Rietveld. 1978. Helminth and arthropod parasites of black bear, Ursus americanus, in central Ontario. Canadian Journal of Zoology. 56:2122-2126.

Binninger, C. E., J. J. Beecham, L. A. Thomas, and L. D. Winward. 1980. A serologic survey for selected infectious diseases of black bears in Idaho. Journal of Wildlife Diseases. 16(3):423-430.

Briscoe, N., J. G. Humphreys, and J. P. Dubey. 1993. Prevalence of Toxoplasma gondii infections in Pennsylvania black bears, Ursus americanus. Journal of Wildlife Diseases. 29(4):599-601.

Burridge, M. J., W. J. Bigler, D. J. Forrester, and J. M. Hennemann. 1979. Serologic survey for Toxoplasma gondii in wild animals in Florida. Journal of the American Veterinary Medical Association. 175(9):964-967.
Butler, C. E., and R. A. Khan. 1992. Prevalence of Trichinella spiralis in black bears (Ursus americanus) from Newfoundland and Labrador, Canada. Journal of Wildlife Diseases. 28(3):474-475.

Chomel, B. B., R. L. Zarnke, R. W. Kasten, and P. H. Kass. 1995. Serologic survey of Toxoplasma gondii in grizzly bears (Ursus arctos) and black bears (Ursus americanus), from Alaska, 1988 to 1991. Journal of Wildlife Diseases. 31(4):472-479.

Conti, J. A., D. J. Forrester, and J. R. Brady. 1983. Helminths of black bears in Florida. Proceedings of the Helminthological Society of Washington. 50:252256.

Crum, J. M., V. F. Nettles, and W. R. Davidson. 1978. Studies on endoparasites of the black bear (Ursus americanus) in the southeastern United States. Journal of Wildlife Diseases. 14:178-186.

Dies, K. H. 1979. Helminths recovered from black bears in the Peace River region of northwestern Alberta. Journal of Wildlife Diseases. 15:49-50.

Dubey, J. P., et al. 1995. Prevalence of viable Toxoplasma gondii tissue cysts and antibodies to T. gondii by various serologic tests in black bears (Ursus americanus) from Pennsylvania. Journal of Parasitology. 81(1):109-112.

Dubey, J. P., M. J. Topper, and F. B. Nutter. 1998. Muscular Sarcocystis infection in a bear (Ursus americanus). Journal of Parasitology. 84(2):452-454.

Dubey, J. P., N. Briscoe, R. Gamble, D. Zarlenga, G. Humphreys, and P. Thulliez. 1994.

Characterization of Toxoplasma and Trichinella isolates from muscles of black bears in Pennsylvania. American Journal of Veterinary Research. 55(6):815819.

Duffy, M. S., T. A. Greaves, and M. D. B. Burt. 1994. Helminths of the black bear, Ursus americanus, in New Brunswick. Journal of Parasitology. 80(3):478480.

Duncan, R. B., D. Caudell, D. S. Lindsay, and H. D. Moll. 1999. Cryptosporidiosis in a black bear in Virginia. Journal of Wildlife Diseases. 35(2):381383.

Farrell, R. K., R.W. Leader, and S. D. Johnston. 1973. Differentiation of salmon poisoning disease and Elokomin fluke fever: Studies with the black bear (Ursus americanus). American Journal of Veterinary Research. 34(1):919-922.

Foreyt, W. J., S. C. Schell, and J. C. Beyer. 1996. Prouterina wescotti N. Gen., N. Sp. (Trematoda: Prouterinidae N. Fam.) from the brain, lungs, and nasal sinuses of a black bear (Ursus americanus) from Idaho. Journal of Wildlife Diseases. 32(2):225233. 
Foreyt, W. J., W. H. High, and R. L. Green. 1999. Search for the trematode Prouterina wescotti in black bears in Oregon. Journal of Wildlife Diseases. 35(3):622-623.

Forrester, D. J. 1992. Parasites and Diseases of Wild Mammals in Florida. University Press of Florida: Gainesville, FL.

Forrester, D. J., M.G. Spalding, and J.B. Wooding. 1993. Demodicosis in black bears (Ursus americanus) from Florida. Journal of Wildlife Diseases. 29(1):136-138.

Foster, G. W., T. A. Cames, and D. J. Forrester. 1998. Geographical distribution of Demodex ursi in black bears from Florida. Journal of Wildlife Diseases. 34(1):161-164.

Frechette, J. L., and M. E. Rau. 1977. Helminths of the black bear in Quebec. Journal of Wildlife Diseases. 13:432-434.

Frechette, J. L., and M. E. Rau. 1978. Seasonal changes in the prevalence of ova of Diphyllobothrium ursi and Baylisascaris transfuga in the feces of the black bear (Ursus americanus). Journal of Wildlife Diseases. 14:342-344.

Hair, J. D., and J. L. Mahrt. 1970. Eimeria albertensis n. sp. An E. borealis n. sp. (Sporozoa: Eimeriidae) in black bears, Ursus americanus, from Alberta. Journal of Protozoology. 17:663-664.

Johnson, C. A. 1975. Ursus americanus (black bear) a new host for Dirofilaria immitis. Journal of Parasitology. 61(5):940.

Jonkel, C. J., and I. T. Cowan. 1971. The black bear in the spruce-fir forest. Wildlife Monographs: A Publication of the Wildlife Society.

King, J. M., H. C. Black, and O. H. Hewitt. 1960. Pathology, parasitology and hematology of the black bear in New York. New York Fish and Game Journal. 7(2):99-111.

Kirkpatrick, C. E., D. A. Leiby, D. Abraham, and C. H. Duffy III. 1986. Gongylonema pulchrum Molin (Nematoda: Gongylonematidae) in black bears (Ursus americanus Pallus) from Pennsylvania. Journal of Wildlife Diseases. 22(1):119-121.

LeCount, A. L. 1981. A survey of trichinosis among black bears of Arizona. Journal of Wildlife Diseases. 17(3):349-351.

Levine, N. D. 1968. Nematode parasites of domestic animals and man. Burgess Publishing Company: Minneapolis, MN.

Levine, N. D. 1980. Nematode parasites of domestic animals and of man, 2nd edition. Burgess Publishing Company: Minneapolis, MN.

Manville, A. M. 1978. Ecto- and endoparasites of the black bear in northern Wisconsin. Journal of
Wildlife Diseases. 14:97-101.

Nutter, F. B., J. F. Levine, M. K. Stoskopf, H. R.

Gamble, and J. P. Dubey. 1998. Seroprevalence of Toxoplasma gondii and Trichinella spiralis in North Carolina black bears (Ursus americanus). Journal of Parasitology. 84(5):1048-1050.

Pence, D. B., J. M. Crum, and J. A. Conti. 1983.

Ecological analyses of helminth populations in the black bear, Ursus americanus, from North America. Journal of Parasitology. 69(5):933-950.

Petrochenko, V. I. 1971. Acanthocephala of domestic and wild animals. Israel Program for Scientific Translation, Ltd: Jerusalem, Israel.

Quinn, P. J., R. O. Ramsden, and D. H. Johnston. 1976. Toxoplasmosis: A serological survey in Ontario wildlife. Journal of Wildlife Diseases. 12:504-509.

Rausch, R. L. 1954. Studies on the helminth fauna of Alaska XXI. Taxonomy, morphological variation, and ecology of Diphyllobothrium ursi n. sp. Provis. on Kodiak Island. Journal of Parasitology. 40:540-563.

Rogers, L. L. 1975. Parasites of black bears of the Lake Superior region. Journal of Wildlife Diseases. 11:189-192.

Ruppanner, R., D. A. Jessup, I. Ohishi, D. E. Behymer, and C. E. Franti. 1982. Serologic survey for certain zoonotic diseases in black bears in California. Journal of the American Veterinary Medical Association. 181(11):1288-1291.

Schad, G. A., D. A. Leiby, C. H. Duffy, K. D. Murrell, and G. L. Alt. 1986. Trichinella spiralis in the black bear (Ursus americanus) of Pennsylvania: Distribution, prevalence and intensity of infection. Journal of Wildlife Diseases. 22(1):36-41.

Schmietzel, L., and M. Fowler. 1984. Successful treatment of audycoptid mange in a black bear. Journal of the American Veterinary Medical Association. 185(11): 1433.

Schmitt, S. M., T. M. Cooley, and P. D. Friedrich. 1987. Clinical mange of the black bear (Ursus americanus) caused by Sarcoptes scabiei (Acarina, Sarcoptidae). Journal of Wildlife Diseases. 23(1):162165.

Smith, H. J. 1978. Status of trichinosis in bears in the Atlantic Provinces of Canada 1971-1976. Canadian Journal of Comparative Medicine 42:244245.

Strickland, R. K., R. R. Gerrish, J. L. Hourigan, and G. O. Schubert. 1976. Ticks of veterinary importance. APHIS-USDA Agriculture. Handbook No. 485. U.S. Government Printing Office: Washington, D.C. 
Theis, J. H., M. Cleary, M. Syvanen, A. Gilson, P. Swift, J. Banks, and E. Johnson. 1996. DNA-confirmed Taenia solium cysticercosis in black bears (Ursus americanus) from California. American Journal of Tropical Medicine Hygiene. 55(4):456-458.

Wilkinson, P. R. 1970. Dermacentor ticks on wildlife and new records of paralysis. Proceedings of the Entomological Society of British Columbia. 67:24-29.

Xiao, L., J. R. Limor, I. M. Sulaiman, R. B. Duncan, and A. A. Lal. 2000. Molecular characterization of a Cryptosporidium isolate from a black bear. Journal of Parasitology. 86(5):1166-1170.

Yunker, C. E., C. E. Binninger, and J. E. Keirans. 1980. Clinical mange of the black bear, Ursus americanus, associated with Ursicoptes americanus (Acari: Audycoptidae). Journal of Wildlife Diseases. 16(3):347-356.

Zarnke, R. L., J. P. Dubey, O. C. H. Kwok, and J. M. Ver Hoef. 2000. Serologic survey for Toxoplasma gondii in selected wildlife species from Alaska. Journal of Wildlife Diseases. 36(2):219-224.

Zemen, D. H., J. P. Dubey, and D. Robison. 1993. Fatal hepatic sarcocystosis in an American black bear. Journal of Veterinary Diagnostic Investigation. 5:480-483.

Zimmermann, W. J. 1970. The epizootiology of trichiniasis in wildlife. Journal of Wildlife Diseases. 6:329-334. (잣

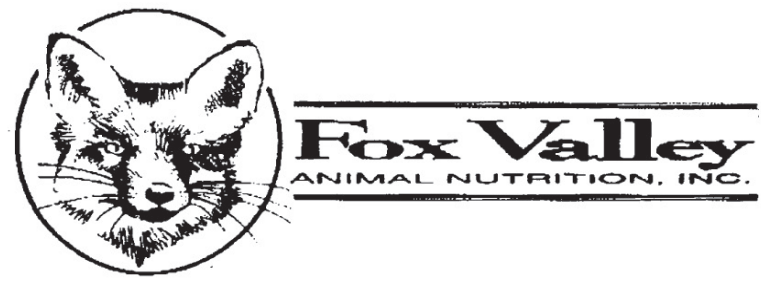

DAY ONE FORMULAS ARE SPECIES SPECIFIC MILK REPLACERS FOR DOMESTIC, EXOTIC, AND WILDLIFE MAMMALS USING HIGH QUALITY INGREDIENTS.

ALSO OFFERING:

LA 200 LACTOBACILLUS ACIDOPHILUS

DIA STAT 200 to normalize stool consistency ELECTRO STAT 200 electrolyte

ULTRA BOOST high fat cream additive ULTRA WEAN weaning formula (all in powder form) CATAC NURSER BOTTLES AND TEATS SNUGGLE SAFE microwaveable heat pads O-RING SYRINGES

Visit our web site: foxvalleynutrition.com sales/tech: 800-679-4666 fax 815-578-4240

\section{MYNTEED:}

Enthusiastic individuals who want to learn more about wildlife rehabilitation in a casual atmosphere that is conducive to enjoyment while learning and networking.

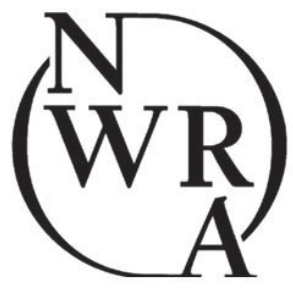

Symposium 2007

March 13-17, 2007 Chicago, IL

www.nwrawildlife.org 